\title{
MICROBIOLOGICAL SURVEY AND DISSEMINATION OF FILAMENTOUS FUNGI OF PUBLIC HEALTH SIGNIFICANCE FROM WATER RESERVOIR (STORAGE TANK) IN CROWN ESTATE, IGBINEDION UNIVERSITY, OKADA, NIGERIA
}

\author{
*Enaigbe, A.A $A^{l(\mathbb{D})}$ Akpoka, O. A. ${ }^{l(D)}$, Okafor-Elenwo, E.J ${ }^{l(\mathbb{D})}$, Ogboghodo I. $B^{2}$
}

Address (es): Olubusola Odeniyi,

${ }^{1}$ Department of Biological Sciences, College of Applied and Natural Sciences, Igbinedion University, Okada, Nigeria.

${ }^{2}$ Department of Microbiology, Faculty of life Sciences, University of Benin, Nigeria.

*Corresponding author : andrewenaigbe89@gmail.com

https://doi.org/10.36547/ft.2020.3.3.20-22

\section{ABSTRACT}

Results of this investigation revealed that several species of filamentous fungi are present in the reservoir waters. Samples were collected from the surface and walls of the inner storage tank. The isolation process was done by a range of techniques and media, monitored by trained taxonomist to achieve broad arrays of water-borne fungi classified to species level. The direct plate enrichment counts and filtration technique recorded the highest number of counts (59\% and $32 \%)$ respectively. The sabauraud dextrose Agar (SDA) was observed as the medium that recorded the highest colonies $(60 \mathrm{cfu} / 100 \mathrm{ml})$ for incubation period of $5 \mathrm{~d}$ at $30^{\circ} \mathrm{C}$. Six different fungal taxa were recovered from the three examined sites (ST1, ST2 and ST3) and the ST3 was reported to have the highest number of isolated species. However, certain fungi were observed to be more distributed than others, specifically in species of Aspergillus and Penicillium which tended to be the most common. Although, species of other genera such as Acremonium sp., Rhizopus stolonifer, Mucor racemosus and Trichophyton sp. were also present but in low counts. The significance of fungi in water systems is lowly expressed as many of the species isolated from water sources are confirmed to possess the potentiality of secreting toxic secondary metabolites like patulin, produced by $P$. espansum causing immune-suppression in hosts, A.flavus secrets aflatoxins that can be carcinogenic, A. versicolour releases the musty odours in homes, while some moulds are concerned in food deterioration.

Keywords: Filamentous fungi, isolation techniques, mycotoxins, reservoir and heath relevance

\section{INTRODUCTION}

The filamentous fungi consists of long structure known as filamentous hyphae which are extended to derive nutrients from substrates and produced for vegetative non-sexual reproduction with spores or cornidia and a vast are human pathogens. Fungi are constantly present in different water sources and their impacts lead to many biological processes such as biodegradation, biodeterioration, biofilm and its aesthetic health issues that are of enormous challenges to water-related regulatory agencies.

Fungi secrete digestive enzymes to breakdown biomolecules into simpler elements, prior to utilization as nutrients and in production of mycotoxins such as aflatoxins, fuminisins and zearalenons that are inimical to humans' health. The adverse effects ranged from being used as biological and chemical weapons introduced into water distribution systems, production of cadaverine and putrescine with pungent irritating odour. Though, they are useful in synthesis of antibiotics and other $\beta$-lactams and as biological pesticides to control weeds and pests (Espinale \& Montero, 2004).

An alarming increase in the number of pathogenic diseases due to filamentous fungi is attributed to the increase in patients undergoing immunosuppressive therapies, organ transplants and acquired immune deficiency syndrome (AIDS) patients. The most common organisms responsible for this trend are the Aspergillus and Penicillium. The systematic investigation of fungi in drinking water system is on the increase, because it is usually performed when cases of contamination are reported. A limited number of tests revealed that, fungi are present in a significant amount in stored water samples, but the range of species is extremely variable (Ferrti \& Demoraes, 2001). The objective of this study was to detect whether the storage tank in Crown Estate of Igbinedion University, Okada, Nigeria is a source of filamentous fungi of public health importance.

\section{MATERIALS AND METHODS}

\section{Sample Collection}

Water samples were collected from three water reservoirs (storage tanks) with each above 100,000 litres in the month of March, 2019 on weekly basis in the Crown Estate, Igbinedion University, Okada, Nigeria. Sterile bottles were sufficiently quantified with sodium thiosulphate to neutralize the chlorine. Five hundred millilitre $(500 \mathrm{ml})$ water samples were obtained and stored at $4{ }^{\circ} \mathrm{C}$ before the isolation was performed within $24 \mathrm{hr}$. A direct collection approach was used whereby the bottles were inserted onto the storage tank from the top and allowed to fill gently.

\section{Isolation}

This involved the concentration of fungi propagules and filtration processes.

\section{Concentration}

This is the trapping of propagules found in the sample by centrifugation at 2000 resolution per minute (rpm). The fungi contained in the sample were observed directly or allowed to grow and seen as colonies.

\section{Filtration}

One hundred milliliter of reservoir water samples was filtered through a presterilized $0.45 \mu \mathrm{m}$ Millipore filter paper and aseptically transferred onto an agar medium in $10 \mathrm{~cm}$ petri dishes for $5 \mathrm{~d}$ at $30^{\circ} \mathrm{C}$. Four media that are cheap, simple and with good results were used in the test and these include half corn meal agar (CMA/2), neo-pentose-glucose-rose Bengal agar (NGRBA), sabouraud dextrose agar (SDA) and oomycetes selective medium (OSM). The observation of the filtered sample was carried out by microscopy.

\section{Baiting}

This test was mainly to determine the zoospore fungi (Oomycetes) and conducted as described (Virginin $\boldsymbol{e t}$ al., 2011) with slight modifications. Many pieces of 1.0 $\mathrm{cm}$ sterilized snake skin and hallucinogenic seeds of tobacco plants were added to $100 \mathrm{ml}$ fraction of samples in shake-flask incubated for $5 \mathrm{~d}$ at $30^{\circ} \mathrm{C}$, during which period, any baits accompanied with presumed evidence of fungi colonies were aseptically accepted and transferred onto oomycetes selective medium (OSM) and samples plated out in duplicates.

\section{Swapping}

The swab was collected by using a scalpel-fixed with cotton wool at the tip to scrap the wall of the inner surface of the water reservoir. The obtained swab was then rinsed in saline solution (Nacl, $1.0 \% \mathrm{w} / \mathrm{v})$. A sample $(0.1 \mathrm{ml})$ spread evenly over the medium surface, then dispensed into petri-dishes and incubated for $5 \mathrm{~d}$ at $30^{\circ} \mathrm{C}$. The media employed were CMA/2; NGRBA and SDA. 


\section{Enrichment}

This was done by inoculating $10 \mathrm{ml}$ of diluted sample suspension onto $90 \mathrm{ml}$ of SDA in shake-flask. Sub-samples $(1.0 \mathrm{ml})$ were then inoculated onto the medium in plates, incubated for $48 \mathrm{hr}$ at $25^{\circ} \mathrm{C}$ and observed for the growth of fungal colonies. This test was conducted to cater for samples with low fungi colonies.

\section{Enumeration and Identification}

All colonies on agar plates were counted and recorded as colony forming unit $(\mathrm{cfu} / 100 \mathrm{ml})$ of water. The fungi were identified on the platform of macroscopic and microscopic characteristics. However, most Aspergillus was identified to species level according to procedures outlined (Kimsey et al., 2010).

\section{RESULTS}

Table 1 Number and percentage of different fungal colonies recorded by various methods and media

\begin{tabular}{|c|c|c|c|c|}
\hline Media & Filtration & baiting & Plating & swabbing \\
\hline CMA/2 & 18 & - & 20 & 1 \\
\hline NGRBA & 10 & 2 & 34 & 3 \\
\hline OSM & 2 & 3 & 14 & 3 \\
\hline SDA & 25 & 1. & 32 & 2 \\
\hline All media & $55(32.0 \%)$ & $6(3.5 \%)$ & $\begin{array}{c}100(59.0 \\
\%)\end{array}$ & $9(5.3 \%)$ \\
\hline
\end{tabular}

Key: NGRBA - Neo-pentose- glucose Bengal agar; OSM - Oomycetes selective medium; SDA - Sabouraud dextrose agar; DP - direct plating NGRBA - Neo-pentose- glucose Bengal agar; OSM - Oomycetes selective medium; SDA - Sabouraud dextrose agar; DP - direct plating

The baited and swabbed methods employed in this study recorded low number of fungal isolates. There was an estimated reduction of counts compared to the overall fungal counts (Table 1). The surfaces of the baits tended to be completely covered with bacteria and yeast cells which reduced the number of counts and the dryness of the inner wall of the water reservoir also contributed to the low counts recorded. Nevertheless, 6 fungal $(\mathrm{CFU} / \mathrm{ml})$ was obtained from baiting and 9 fungal $(\mathrm{CFU} / \mathrm{ml})$ was recorded from swabbing methods respectively. The direct plating and filter techniques recorded highest values of fungal colonies (100 and 55 $\mathrm{CFU} / \mathrm{ml}$ ). The NGRBA provided the highest recovering of filamentous fungi (34 out of 100) were detected using enrichment plate method (Table 1).

The fungal propagules microscopically examined showed that, the cornidia were more produced in all the media used with average score (5.3) and the sclerotia recorded the least mean $(0.3)$ (Table 2$)$

Table 2 Mean of propagules on $1.0 \mathrm{~cm}$ pieces of filter employed from stored water sample sites

\begin{tabular}{|l|c|c|c|}
\hline Isolation & hyphae & $\begin{array}{c}\text { Spores } \\
\text { (cornidia) }\end{array}$ & sclerotia \\
\hline ST1 & - & 4 & 1 \\
ST2 & 3 & 2 & 10 \\
ST3 & 2 & 5 & - \\
Mean & 1.7 & 5.3 & - \\
\hline
\end{tabular}

The table below showed the dissemination of organisms based on the isolation methods and media used; the species obtained were of 5 genera, the most abundant were Aspergillus and Penicillium which accounted for $63 \%$. The other organisms were Acremonium simplex, Rhizopus stolonifer, Mucor racemosus and Trychophyton sp. estimated at $37 \%$. The Aspergillus identified to species level included; A.flavus, A fumigatus and A. versicolour, while the Penicillium species were $P$. brevicompacum and $P$. espansum. Overall, all fungi were accordingly isolated from the three surveyed sites (ST1, ST2 and ST3) though the highest number of fungi was recorded in ST3, A. fumigatus and P. brevicopacum were present in all the sites investigated.
Table 3 Methods and media used in isolation for various fungal group

\begin{tabular}{|c|c|c|c|}
\hline Organisms & $\begin{array}{l}\text { Sites of } \\
\text { isolation }\end{array}$ & Methods & Media \\
\hline $\begin{array}{l}\text { Acremonium } \\
\text { simplex }\end{array}$ & 2,3 & $\begin{array}{c}\text { Filtration, direct } \\
\text { Plating(DP), swab }\end{array}$ & $\mathrm{CMA} / 2, \mathrm{SDA}$ \\
\hline Aspergillus flavus & 1,3 & Baiting filtration & $\begin{array}{c}\text { NGRBA, } \\
\text { CMA/2, OSM }\end{array}$ \\
\hline $\begin{array}{l}\text { Aspergillus } \\
\text { fumigatus }\end{array}$ & $1,2,3$ & $\begin{array}{c}\text { Baiting, DP, } \\
\text { Filtration }\end{array}$ & $\begin{array}{c}\mathrm{CMA} / 2, \mathrm{SDA}, \\
\text { NGRBA }\end{array}$ \\
\hline $\begin{array}{l}\text { Aspergillus } \\
\text { versicolor }\end{array}$ & 1,2 & & \\
\hline $\begin{array}{l}\text { Penicillium } \\
\text { brevicompacium }\end{array}$ & $1,2,3$ & & $\begin{array}{l}\text { NGRBA, } \\
\text { OSM }\end{array}$ \\
\hline Penicillium espasum & 1,3 & $\begin{array}{l}\text { DP, filtration, } \\
\text { baiting }\end{array}$ & $\begin{array}{c}\text { NGRBA, } \\
\text { OSM, SDA }\end{array}$ \\
\hline Mucor racemosus & 1,3 & DP, filtration, swab & $\mathrm{CMA} / 2, \mathrm{SDA}$ \\
\hline \multicolumn{4}{|l|}{ Rhizopus stolonifer } \\
\hline Trychonphyton sp. & 3 & DP, filtration, swab & All media \\
\hline
\end{tabular}

Key: NGRBA - Neo-pentose- glucose Bengal agar; OSM - Oomycetes selective medium SDA - Sabouraud dextrose agar; DP - direct plating

\section{DISCUSSION}

The identification of vast number fungi is primarily based on morphological and microscopic convectional techniques of spore-bearing structures. Six genera were recovered from the three sites analyzed to include Aspergillus, Penicillium, Acremonium, Rhizopus, Mucor and Trychophyton. However, they contain variable number of species and therefore needed much attention to identify them to species level. The investigative methods and resources available as enunciated by Mirian et al. (2007) have enabled broad spectrum of isolation and identification realistic and a lot of fungi observed in the reservoir which were not water-related microorganisms.

The method employed that gave the highest count was the serial dilution enrichment plate method involving different media at incubation time of $5 \mathrm{~d}$ for $30{ }^{\circ} \mathrm{C}$. This study disclosed that, reservoir of Crown Estate, Igbinedion University, Okada is a source of filamentous fungi (ff) ultimately due to prevailing environmental conditions, isolation and growth media used. The growth of ff could be inhibited by the presence of bacteria and yeast cells competing for nutrients and toxins often released by $\mathrm{ff}$ can clear the proliferation of other microbes in the system. In this analysis, few organisms were recorded by the swabbing approach, thereby indicating that biofilm development had not occurred on the inner wall of reservoir.

The media devoid of antibiotics with raised ff level may indicate that chemotherapeutic substances have been produced by the fungi. The Aspergillus and Penicillium recorded highest number of occurrence (Table 3). Briza et al. (1989); Jose (1967) declared that $P$. espansum, secretes chemicals that damage post-harvest diseases of apples and patulin (immune-suppressive toxin), $P$. bravicompactum produces mycophenolic acid that causes animal and human diseases such as oesophageal cancer, hormonal disorder and benign endemic nephropathy. Aspergillus flavus produces gliotoxin that suppresses the function of immune system and aflatoxin responsible for chronic granulomatous sinusitis, keratitis and wound infection. A. versicolour causes musty odours in homes and produces hepatotoxic and carcinogenic mycotoxins, while A. fumigatus produces gliotoxin that is immuno suppressive, and fumagillin that is cyclohexane derivative, known as inhibitor of endothelial cell proliferation. The Acremonium releases octenol, linked to odours, Trychophyton sp. is concerned with skin, toe, hair and nail infections and the Rhizopus and Mucor are involved in decomposition and spoilage of food substances.

In the study of Virginin et al. (2011) Alternaria alternata, Aspergillus niger, $P$. espansum, P. bravicompactum, few molds and Trychophyton mentagrophyte were detected in water systems in low counts. Differences in genera observed is adduced to conditions such as raw water sources, system hydraulics, water temperature patterns, maintenance and infrastructural systems from which the samples were collected. Despite the fact that all the fungi were obtained from the suspension, deriving reliable data for this analysis was difficult. This is thought to be due to the mycelial type of filamentous fungi which is capable of disintegrating into irregular structures to initiate their own growth and also as a result of the difference in fungi cornidia hydrophobicity which are uniformly distributed or aggregated, as some agglutinate due to thick gelatinous coatings (Cast, 2013). Realizing this fact, it is not possible to suggest a specific medium for growth, though numbers were recovered in all media. Although, all the fungi were recovered from the suspensions, obtaining ideal data for these organisms proved tedious. 


\section{CONCLUSION}

Fungal proliferation in drinking water may be influenced by raw water source, system hydraulics, nutrient concentration and biotic interactions causing severe myco-infections in immunosuppressed hosts resulting from drinking, contact and inhalation of aerosol spores. If further scientific studies suggest an increase in disease risk, pilot epidemiological analysis and surveillance could be performed to checkmate the deleterious menace of fungi dissemination in drinking water systems.

Acknowledgement: This work was carried out as part of research assignment proposed by the Department of Microbiology, Igbinedion University, Okada, Nigeria and authors are solely responsible for the outcome which does not represent the opinion of the University community.

\section{REFERENCES}

Borman, A.R. (2016). Evaluation of viability of filamentous fungi after prolonged storage in enclosed tank. Mycopathologia, 106, $73-79$. https://doi.org/10.1007/s11046-006-0023-z.

Briza, P. Ellengu, A., \& Winklen, G. (1988). Chemical composition of the yeastascospore cellwall. Journal of Biological Chemistry, 263, 1567 - 1574. https://www.jbc.org/content/263/23/11569.long

Cast, P.Z. (2013). Dynamics of Microbial Water Sediments. Cambridge University Press, UK. 210pp.

Espinele, A., \& Montero, D. (2004). Long term preservation of fungi isolates in prepared oxyogenic microbank. Journal of Clinical Microbilogy, 42, 1257 - 1259. http://doi.org/10.1128/JCM.42.3.1257-1259.2004

Feretti, R., \& Demoraes, C. (2001). Viability, morphological characteristics and dimorphic ability of fungi preserved by different methods. Revised Mycology, 18, 191 - 196. http://www.reviberoammicol.com/pubmed linkout.php?18p191

Jose, R. (1967). Chemical components of the cell wall of Aspergillus species. Archives of Biochemistry and Biophysics, 122(1), $118-125$. https://doi.org/10.1016/0003-9861(67)90130-0

Kinsey, G.C., Paterson, R., \& Kelly, J. (2010). Methods for the examination of filamentous fungi in treated and untreated water. Journal of Applied Microbiology, 32, 56 - 64. https://doi.org/10.1111/j.1365-2672.1998.tb05301.x Miriam, U.Y., Rita de Cassia, P.P., Suell, Y.O., \& Celso, U.N. (2007). Yeasts and filamentous fungi in bottled mineral water and tap water from municipal supplies. Brazil archives of Biology and Technology, 50(1), $111-118$. http://dx.doi.org/10.1590/S1516-89132007000100001

Virginin, M.S., Helena, M.B., Olivera, C.R., \& Nelson, C. (2011). Filamentous fungi in drinking water particularly in relation to biofilm formation. International Journal of Environmental Research and Public Health, 8(2), 456 - 469. http://doi.org/10.3390/ijerph8020456 